\title{
SESSÃO ORDINÁRIA: ANÁLISE DOS DISCURSOS DOS PRESIDENTES DA PROVÍNCIA DE GOIÁS NA CONSTRUÇÃO DA FEMINIZAÇÃO DO MAGISTÉRIO NO SÉCULO XIX
}

\author{
RODRIGO SILVA ROCHA \\ SANDRA ElAINe AIreS De Abreu \\ Universidade Estadual de Goiás (UEG), Anápolis, Goiás, Brasil
}

\begin{abstract}
Resumo: Neste artigo analisamos os discursos dos presidentes da Província de Goiás para a construção da feminização do magistério no século XIX. As discussões se baseiam principalmente nas contribuições de Bretas (1991), Brandão (2012), Charaudeau e Maingueneau (2012), Maingueneau (2008a/, 2008c), Bakhtin (2010), Fairclough (2001) e Ramalho e Resende (2011). Trata-se de uma investigação qualitativa, com objetivo exploratório e procedimentos bibliográfico e documental. Os resultados apontam, entre outros, que não havia uma tendência a inserir as mulheres no exercício do magistério, bem como o debate sobre gênero não estava posto, mas, ao que tudo indica, havia segregação pautada na norma moral da época. Nesse sentido, a feminização do magistério na Província de Goiás foi uma construção fomentada no decorrer do Brasil Império.
\end{abstract}

Palavras-chave: Feminização. Instrução. Goiás. Discurso.

\section{INTRODUÇÃO}

A inserção das mulheres no magistério primário no Brasil ocorreu com o Decreto Lei Imperial de 15 de outubro de 1827, que criou as escolas femininas (art.11) a serem regidas por mulheres, que receberiam os mesmos salários que os homens (art. 13), e com o currículo diferenciado (art.6 e 12). No entanto, esse decreto-lei foi revogado pela Lei no. 16 de 12 de agosto de 1834, conhecida por Ato Adicional, que no artigo 10 determinou que as Assembleias Legislativas Provinciais deveriam legislar sobre a instrução pública.

A partir do Ato Adicional, as províncias passaram a estabelecer suas legislações educacionais. Assim, Goiás, no referido período, estabeleceu a Lei nº 13 de 23 de junho de 1835 e seis regulamentos de instrução' ${ }^{1}$. Manteve as escolas masculinas e femininas regidas por homens e mulheres, respectivamente. Embora, o momento histórico colocasse a divisão, escolas masculinas e femininas, a discussão sobre feminização não fazia parte do momento histórico. Mas, iniciava-se a construção de uma profissão dentro do funcionalismo público cuja parcela destinava-se às mulheres. Consideramos que, nesse período, mesmo que o tema feminização não fizesse parte da pauta dos presidentes provinciais, o fenômeno começava a ser construído. 
Dessa maneira, as professoras assumiram a regência das escolas mistas no fim do período imperial, por volta de 1884, quando na Província de Goiás os presidentes instituíram as escolas mistas (para meninos e meninas), e essas escolas só poderiam ser regidas por mulheres. Nesse contexto, questionamos: o que levou o governo goiano a instituir que as escolas mistas fossem regidas apenas por professoras? Seria o início de uma suposta feminização do magistério em Goiás?

Como analisamos os discursos dos presidentes da Província de Goiás para construção da feminização do magistério no século XIX, consideramos também necessário apresentar algumas ideias fundantes da Análise do Discurso ${ }^{2}$ e, assim, tentar responder as essas perguntas que não estavam obviamente manifestadas nos relatórios dos presidentes da Província de Goiás ${ }^{3}$, a partir do advento das escolas mistas.

Por fim, o texto a seguir está estruturado em duas vertentes: a) historiografia do magistério público feminino de Goiás, isto é, situando o leitor no tempo e espaço sob investigação e b) Análise do Discurso, marcada pela subjetividade exteriorizada nos discursos dos presidentes da Província de Goiás Antero Cicero D’Assiz, Luiz Augusto Crespo e Aristides de Souza Spinola, entre os anos 1870 a 1884.

\title{
INSTRUÇÃO PÚBLICA PARA PROFESSORAS
}

Compreendemos que a atividade docente no Brasil foi iniciada por homens, em particular os jesuítas no período colonial. Mas foi a partir do Decreto Lei Imperial de 15 de outubro de 1827 que foi possível vislumbrar algumas mudanças que demonstraria a presença feminina na sala de aula das províncias do Brasil. Com a revogação do referido decreto-lei imperial, o Ato Adicional de 12 de agosto de 1834 estabeleceu no artigo 10 que as assembleias legislativas provinciais gozariam de maior autonomia e com isso deveriam estabelecer sua própria lei educacional. Bretas, a propósito, declarou que:

\begin{abstract}
A lei de 15 de outubro, no seu artigo $11^{\circ}$, pela primeira vez no Brasil, mandava criar escolas públicas para meninas, nas cidades, vilas e lugares mais populosos, onde os presidentes, em conselho, julgassem necessárias. Com base nesse dispositivo, o Conselho da Província de Goiás propôs ao Governo Central a criação de uma escola feminina em Natividade e outra na Capital. A de Natividade foi criada por Lei 7 de junho de 1831, da Assembléia Geral. A da cidade de Goiás foi criada por decreto de 25 de outubro do mesmo ano, da Regência. Aquela teve a primazia da criação, mas a primeira a ser realmente aberta foi a da Capital, com o provimento na cadeira de Maria Romana da Purificação, por concurso, em setembro de 1832. A de Natividade só foi provida em 18 de junho de 1837, na pessoa de Leocácia Antônio dos Santos. Estas foram as duas únicas escolas femininas criadas em Goiás pela Regência, durante a vigência da lei 15 de outubro. (1991, p. 138).
\end{abstract}

Tais considerações apontam que a admissão da mulher, quer sejam alunas, quer sejam professoras, à instrução formal foi vagarosa e gradual não apenas em Goiás, mas em toda a corte, sendo marcada, em especial, pelo refreamento de uma sociedade que 
via com temor a instrução e o magistério feminino. Esse ingresso se consolidaria a partir da segunda metade do século XIX, vindo a se fortalecer no final do século (BARREIROS, 1997).

Em 1835, o Presidente da Província de Goiás, José Rodrigues Jardim, sancionou a Lei no. 13 de 23 de junho de 1835, a primeira lei goiana sobre instrução pública. No artigo 1, estabeleceu a divisão da instrução primária de Goiás em dois níveis. No primeiro, os professores ensinariam a ler, a escrever, as quatro operações aritméticas e a doutrina cristã. No segundo, aplicariam o ensino da gramática da língua nacional e noções dos deveres morais e religiosos. As escolas, por sua vez, eram frequentadas apenas pelo alunado masculino, mas, eventualmente, o governo poderia estabelecer escolas para meninas nos lugares em que houvesse a instrução secundária (GOIÁS, 1835).

A partir de 1856, a instrução pública da Província de Goiás obteve o seu primeiro regulamento de instrução com algumas alterações relacionadas ao ensino e às condições das escolas. Em suma, observamos a incorporação de temas como o catecismo, explicações sobre os dogmas fundamentais da doutrina católica e as principais orações. Além disso, a instrução primária para o sexo feminino começava a ter notabilidade. Para elas, além de aprender a ler e escrever, as professoras eram levadas, do mesmo modo, a ensinar as prendas indispensáveis à economia doméstica (art. 2) (GOIÁS, 1856). Logo, continuava às mulheres o dever de promover os meios educativos das crianças, mesmo que pautado no universo doméstico, na moralidade e nas tradições masculinas.

As habilitações e o provimento dos professores na Província de Goiás eram realizados via exame na presença do Presidente da Província, do Inspetor Geral de Instrução e de mais pessoas nomeadas pelo presidente. As etapas do exame consistiam em fazer exercício de leitura; escrever frases alternadas; escrever algumas linhas em bastando, bastardinho e cursivo; resolver questões de aritmética e responder perguntas sobre a religião católica (art. 10). Eram esses os meios que o examinador, o Inspetor Geral de Instrução Pública, dispunha para sondar os conhecimentos e analisar a moral do candidato. Ainda dentro desse grupo de fatores, no concurso para professoras, o Presidente da Província designava uma senhora ou uma professora pública para julgar as habilidades e os trabalhos de agulha e bordado (GOIÁS, 1856).

No regulamento de instrução pública e particular de 1869, além de concurso para exercer o magistério público, as professoras deveriam apresentar certidão de casamento e autorização do marido, no caso das senhoras casadas; certidão de óbito do marido, para viúvas, e certidão de sentença de divórcio, para os casos de separação judicial. Ainda de acordo com o artigo 11, a nomeação de professora para senhoras solteiras ocorria aos 25 anos de idade ou aos 21, se morasse com os pais ou tutores. Acrescentamos que nas escolas femininas, além das matérias de leitura, escrita, gramática e sistemas de pesos e medidas, os trabalhos de agulha eram um conhecimento a ser ensinado (GOIÁS, 1869).

Já o regulamento da instrução pública de 1884 estabeleceu que nos distritos mais populosos da Província de Goiás haveria uma escola de primeiro grau para o sexo masculino e outra escola para o sexo feminino e, nas vilas, uma escola de segundo grau para o sexo masculino e outra para o feminino (art. 24). Se em décadas anteriores o interesse maior no ensino feminino se localizava nos trabalhos de agulha, nesse período 
é a economia doméstica que constituiu a matéria elementar que deveria ser mais ensinada nas escolas femininas. Esse regulamento instituiu que as professoras conduziriam as escolas mistas e se admitiria crianças até os 11 anos de idade (art. 27), ou seja, quando as escolas masculinas e femininas não tivessem o número mínimo de alunos ou alunas, estas passariam ao regime de escola mista (art. 37) (GOIÁS, 1884).

Com a publicação do regulamento de instrução pública de 1893, inaugurou-se um novo momento na instrução primária de Goiás. Essa autoafirmação de condição reformista que experimentaria a instrução pública de Goiás é revelada no artigo 7 . No documento, nas localidades que não pudessem ter uma escola para cada sexo, poderia ser criada uma escola mista para atendimento daquela freguesia. Entretanto, estas poderiam ser comandadas somente por professoras e com separação de alunos para não haver comunicação entre um e outro sexo (GOIÁS, 1893).

Esse breve histórico sobre a instrução pública para meninas e professoras revela um quadro normativo que subscreve a admissão da mulher à instrução pública, o exercício de uma profissão que abriu espaço para o funcionalismo público e praticamente graduou o Império do Brasil como o princípio de construção da feminização do magistério em Goiás. Mas, para isso, é preciso entendermos os motivos e a participação dos presidentes da Província de Goiás nesse processo. E, nesse sentido, a Análise do Discurso, abordada no tópico a seguir, oferece artifícios para compreendermos o que supostamente motivou o governo goiano a admitir apenas professoras para a regência de um espaço público (escolas mistas), "até então reservado aos homens ou melhor, aonde a atuação masculina foi sempre valorizada e propalada como natural" (BARREIROS, 1997, p. 110).

\section{ANÁLISE DO DISCURSO}

Em todas as esferas da atividade humana existe produção de discurso. Durante o processo eleitoral, assistimos os discursos políticos; na solenidade de formatura, aguardamos ansiosamente pelo discurso exuberante do orador da turma; no decorrer de uma entrevista de emprego, investimos em um discurso esperando conquistar o trabalho, assim como na elaboração de um e-mail ao cliente, justificando o atraso do produto. Ainda que o discurso seja linguístico e desenvolvido pelo ser humano, o discurso como percebemos nos exemplos acima também é uma atividade social, instável e heterogênea. Para Brandão (2012, p. 2), o discurso é estabelecido como "toda atividade comunicativa entre interlocutores; atividade produtora de sentidos que se dá na interação entre falantes". Isso implica que as pessoas estão imersas em discursos cada vez mais carregados de sentido e ideologias. E esse processo exige, sobretudo, compreendermos as ideologias no interior da linguagem e o sentido que ocorre entre os sujeitos que se comunicam.

Ao pensar no discurso, algumas ideias fundantes devem ser consideradas, como: o evento, isto é, o momento em que o discurso é realizado; as crenças e valores do interlocutor; a geografia e o período histórico do sujeito dentro das instituições que ele participa; a interação entre falantes/ouvintes ou escritor/leitor; a heterogeneidade dialógica, as outras vozes do discurso ou, ainda, o tipo de discurso (orais, escritos ou 
imagéticos). Apesar de o discurso apresentar manifestações sociais, culturais e políticas que marcam a atitude do sujeito, nem sempre o sentido do discurso é dado explicitamente.

O primeiro teorista que buscou entender a análise do discurso foi Michel Pêcheux na década de 1960. Para ele, a análise do discurso era percebida como uma teoria do sentido e para chegar a essa visão do sentido verificou-se as contribuições de outras áreas do conhecimento como a linguística, a sociologia e a psicologia para elaboração de um método. Existem, também, outras variáveis que compõem a Análise do Discurso, como, por exemplo, o marxismo, para formular o conceito de ideologia. De lá para cá, foram inúmeros os estudos que buscaram definir a Análise do Discurso. Mas, para Charaudeau e Maingueneau (2012, p. 43) "é difícil retraçar a história da análise do discurso, pois não se pode fazê-la depender de um ato fundador, já que ela resulta, ao mesmo tempo da convergência de correntes recentes [...]". Apesar de os desfechos serem diversos acerca da gênese e do conceito da análise do discurso, podemos defini-la como um método específico da linguagem para estudar os discursos (ORLANDI, 2003).

Dentro desse âmbito, o discurso dificilmente é apreendido na sua plenitude. Conforme declaramos no início desta seção, todos os campos da atividade humana estão ligados às produções de discursos orais ou escritos. A existência de inúmeros gêneros de discurso impede o seu estudo em um único plano. Para Bakhtin (2010, p. 262), "cada enunciado particular é individual, mas cada campo de utilização da língua elabora seus tipos relativamente estáveis de enunciados, os quais denominamos gêneros do discurso". Ainda que reconhecendo o vasto repertório dos gêneros do discurso, determinados campos da comunicação pressupõem um modelo de enunciado, além de refletir contendas institucionais e de normas. Portanto, nas réplicas diárias de diálogos entre os interlocutores não é favorável o uso, por exemplo, de modalidades ritualizadas como os atos jurídicos, uma vez que o fito neste tipo de gênero é comunicar.

No que tange aos gêneros do discurso, eles ainda podem ser agrupados em primários e secundários. Isso significa que o nível de complexidade é o que determinará a diferença entre os gêneros. Consideramos que os gêneros discursivos primários, ditos simples, emanam dos improvisos, das situações comunicativas ordinárias e do contato imediato entre os interlocutores dentro do mesmo espaço e tempo. Já os gêneros secundários se manifestam de situações mais complexas, nas quais é requisitado do interlocutor um comportamento discursivo mais elaborado, na maior parte dos casos mediado pela escrita (BAKHTIN, 2010). Então, o romance, a petição jurídica, a pesquisa científica e até mesmo os relatórios dos Presidentes da Província de Goiás, abordados neste estudo, são práticas de gêneros discursivos secundários.

De forma geral, os estudos realizados sobre a Análise do Discurso destacam a relevância da constituição dos discursos na evolução da disciplina. Orlandi (2003, p. 8586) enfatiza que "o que caracteriza o discurso, antes de tudo, não é o tipo, é seu modo de funcionamento". Assim, a maneira como o discurso é apresentado e marcado por posição (religiosa, filosófica, científica ou jurídica) é que regulamenta os nichos da sociedade, dando sentido à vida social. Por outro lado, os discursos produzem hierarquia entre os próprios discursos. Maingueneau (2008a, p. 37) cita que "a pretensão desses discursos, assim chamados por nós de 'constituintes', é de não reconhecer outra autoridade além da sua própria, de não admitir quaisquer outros discursos acima deles". Logo, os discursos religiosos não reconhecem, a título de exemplo, os discursos 
científicos, e os discursos científicos, por sua vez, não admitem os discursos religiosos, isto é, não há interação ou aproximação entre eles. Um discurso não exclui o outro, todavia, não aceita a soberania do oposto. Em razão disso existem discursos que operam sobre um plano diferente, de não autoridade. É o caso do discurso político, que não transita entre os discursos constituintes.

Para compreender o fenômeno da feminização do magistério a partir dos discursos dos presidenciáveis de Goiás é, do mesmo modo, imperioso caracterizar a intertextualidade nos referidos discursos. De acordo com Fairclough (2001, p. 134), "todos os enunciados são povoados, e na verdade, constituídos por pedaços de enunciados de outros mais ou menos explícito". Em outras palavras, os discursos são carregados de vozes e de fragmentos de outros discursos. Não por acaso, os relatórios dos presidentes abrangiam vários outros relatórios dos diversos setores do governo imperial. Então, ao captar esses elementos e fazer o refinamento, os sujeitos são capazes de ampliar o próprio discurso e até elevar os gêneros discursivos primários ao nível de secundário, uma vez que eventos comunicativos apresentam circunstâncias potencialmente complexas.

Contudo, não devemos esquecer que a intertextualidade é a causa de muita polêmica nos estudos sobre discurso. Essa afirmação se deve ao fato da dificuldade em determinar a voz que é representada pelo autor no discurso. Fairclough (2001, p. 138), exemplifica que "há sempre uma ambivalência sobre se as palavras reais são atribuíveis à pessoa cuja fala é representada ou ao autor do texto principal". Por isso, não basta discursar ou produzir discurso para ser considerado o autor. É necessário dominar os mecanismos discursivos e assumir a responsabilidade sobre o que diz e como diz.

Outro aspecto fundamental é que na intertextualidade existem duas diferenças substanciais. A primeira refere-se aos discursos, hegemonicamente grafados, que estão presentes sob análise ou o discurso do outro, que está estabelecido por traço ou usualmente por aspas (intertextualidade manifesta). A segunda, intertextualidade constitutiva, relaciona-se aos discursos em que outros discursos são integrados sem que o último (segundo discurso) seja notado. Nesse caso, teremos instituído o discurso direto e o discurso indireto, respectivamente. Essa diferença é elevada, por exemplo, nos discursos dos presidentes Ernesto Augusto Pereira (1869) e Aristides de Souza Spinola (1880).

[...] E deploravel a frequencia que se observa nas escolas da provincia: segundo as ultimas estatisticas á provincia de Goyaz tem uma população de $\mathbf{2 4 0}$ mil almas, destas abatendo-se os escravos e indigenas e considerando-se exagerado o numero poder-se-há considerar a população livre em numero de 150 mil alvas e sobre esse numero calculando-se que 5 por cento sejáo crianças em estado de frequentar as escolas, a frequencia deveria ser 7:500 meninos e todavia devo vos declarar que segundo o relatorio do inspector geral da instrucção publica somente 1:453 alunnos frequentáo as aulas. [...] (Relatorio do presidente da Província de Goiás, Ernesto Augusto Pereira, 1869, p. 24) 
ROCHA, R. S.; ABREU, S. E. A. de

[...] Posso repetir as seguintes palavras escriptas 'pelo actual Director da Instrucção Publica da Bahia, em seu Relatorio de 5 de abril do anno passado: 'Em tudo, maxime em materia de instrucção, sou naturalmente infenso ás bellas theorias irrealisaveis de alguns, que, sentados no recinto calmo de seus gabinetes, pouco attendem á inexequibilidade de seus planos. Haurindo noçóes de muito que coheráo de suas variadissimas leituras, pretendem implantar entre nós germens peregrinos, que bem medráo e vicejáo em outros terrenos e climas, mas que em solo estranho só podem produsir mirrados fructos. Por mais que se queira estatuir a homogeneidade ethnographica da especie humana, sempre será certo que a diversidade de temperamentos, de preconceitos nacionaes, de condiçóes topographicas e queijandas outras circumstancias, estabelecem linhas divisorias entre varios povos do globo, táo pronunciandas e distinctas que, regeital-as, fóra o mesmo que fechar os olhos á esmagadora evidencia dos factos.' [...] (Relatorio do presidente da Província de Goiás, Aristides de Souza Spinola, 1880 , p. 22, grifo do autor)

No primeiro trecho, a oração, "todavia devo vos declarar que segundo o relatorio do inspector geral da instrucção publica somente 1:453 alunnos frequentáo as aulas" revela que o sentido do discurso está comprometido, ou seja, a dificuldade em determinar se a voz é do Presidente ou do Inspetor da Instrução Pública. Por outro lado, o segundo exemplo apresenta claramente que o texto é do Presidente, ou seja, o discurso é marcado pela grafia ":" (dois-pontos) que anuncia a suspensão da voz e a fala do Diretor da Instrução Pública da Bahia. As aspas ainda destacam a parte do texto que não é de autoria do Presidente da Província de Goiás.

\section{RESULTADOS E DISCUSSÃO}

Para iniciar as reflexões, a primeira categoria que abordamos na análise é a modalidade. A modalidade nos estudos analíticos está relacionada ao grau de "afinidade" das proposições presentes nos discursos. Nessa perspectiva, as proposições criam uma relação de sugestão, hipótese ou até mesmo lógica sobre os elementos estabelecidos no texto. Para Hodge e Kress (1988, p. 123 apud FAIRCLOUGH, 2001, p. 199) "o produtor deve indicar um grau de 'afinidade' com a proposição; portanto, qualquer enunciado desse tipo tem a propriedade da modalidade, ou é 'modalizada'". Contudo, as proposições podem ser mapeadas tendo em vista os diferentes graus de afinidades (afirmativas, negativas e indeterminadas) e formas de manifestações. Assim, a modalidade pode acontecer de duas formas: subjetivamente, quando o grau de afinidade do sujeito é explícito no discurso, e objetivamente, quando o grau de afinidade é implícito.

[...] Accresce mais que alguns professores, faltando com franqueza, e feitas honrosas excepções, não inspiram confiança, não estando na altura de sua ardua e importante missão. Acontece não poucas vezes que alguns professores deixão de cumprir seos deveres, e occupão-se de outros misteres alheios ao magisterio; entretanto que obtem attestados de frequencia e bom comportamento, que 


\begin{abstract}
Ihes são dados pelos respectivos inspectores parochiaes, para com elles receberem seos ordenados. [...] relações de amisade e parentesco, dão lugar a que os professores sejão indolentes e menos cuidados no exercicio do magisterio. [...] (Relatório do Inspetor Geral de Instrução Pública, Joaquim Vicente de Azevedo, 1871, p. 27)
\end{abstract}

No fragmento acima, extraído do discurso do Inspetor Geral de Instrução Pública, anexado ao relatório do Presidente da Província de Goiás Antero Cicero D’Assiz (1871), observamos o emprego da expressão "não poucas vezes", que indica um grau de indeterminação em relação à afinidade da proposição e, consequentemente, o Inspetor não consegue consolidar o número de ocorrência do evento "alguns professores deixão de cumprir seos deveres". Do mesmo modo, o Inspetor deixa, ainda, transparecer o seu ponto de vista sobre a situação educacional na província a partir do uso da palavra "sejão" (proposição afirmativa) na oração: "os professores sejão indolentes e menos cuidados no exercicio do magisterio".

Sabemos, por outro lado, que as escolas de instrução primária foram projetadas para reproduzir uma visão de nação brasileira ideal, em que as crianças, especialmente de famílias desafortunadas, e mestres deveriam ser esteio desse ideal. As escolas que esses homens ensinavam forneciam uma instrução fortemente embebida de nacionalismo, higiene, forma física e treinamento pré-vocacional. (D’AVILA, 2006). Porém, o que verificamos foram professores ocupando-se com outros ofícios e descomprometidos com o magistério, escola e qualquer projeto político na província.

Semelhantemente, no excerto abaixo, o presidente da Província de Goiás de 1878, Luiz Augusto Crespo, reúne proposições afirmativas e negativas quando enfatiza que: "um mestre é um homem"; "para elle é servir a Deos e a Patria"; "suppressões é aconselhada"; " não ignorando seus deveres"; "não procurando sahir de sua profissão" e "não a deixando". O chefe provincial promove afirmativas menos categóricas quando avalia que um professor "deve saber muito mais", "deve viver na esphera humilde" e "deve possuir a rara alliança da brandura". Nessa segunda experiência, há uma "sugestão" ao perfil ideal de professor. Ao mesmo tempo e, em conformidade com sua posição ideológica, no íntimo da essência moral e religiosa da época, o presidente delimita o papel do mestre na província e as características que expectava obter em um "bom professor".

[...] Um bom mestre é um homem que deve saber muito mais do que ensina, para ensinar com intelligencia e gosto; deve viver na esphera humilde, e entretanto ter a alma lavada para conservar a dignidade do sentimento, sem o que nunca alcançará o respeito e a confiança das familias; deve possuir a rara alliança da brandura com a firmeza, não ignorando seus deveres; sobre tudo não procurando sahir de sua profissão, porque nesta faz o bem; decidindo a viver e morrer no seio da escola, que para elle é servir a Deos e a Patria. E, não basta o mestre, cumpre tambem, para que a despeza produza resultados proficiuos, que a mocidade corra espontanea á escola com sêde do saber, não a deixando deserta como acontece 
ROCHA, R. S.; ABREU, S. E. A. de

naquellas, cujas suppressões é aconselhada. [...] (Relatório do presidente da Província de Goiás, Luiz Augusto Crespo, 1878, p. 10)

Inferimos, por meio da modalidade subjetiva explícita do Inspetor em 1871 e do Presidente em 1878, que a obrigatoriedade de professoras nas escolas é uma questão de equilíbrio e recurso para solucionar a evasão do professor e do aluno, haja vista a severidade das punições praticadas pelos preceptores e da baixa remuneração dos mestres em razão da decadência dos cofres públicos da província. Essa última identificação, do presidente Luiz Augusto Crespo, notavelmente conhecido por transformar os professores interinos com cinco anos de exercício em vitalícios (ABREU, 2006), corrobora para explicar o abandono do professor com o noviciado e com o magistério.

Ainda na análise dos documentos, é possível a aplicação da categoria coesão. De acordo com Ramalho e Resende (2011, p. 123), a coesão "associa-se ao significado acional/relacional, uma vez que, está diretamente ligada à composição formal do texto". $\mathrm{Na}$ coesão realiza-se a conexão lógico-semântica entre as partes de um texto, cujos objetivos envolvem a elaboração, a extensão e o realce. Esses elementos, não necessariamente nessa ordem e não aplicadas concomitantemente, garantem a harmonia, a ideia e o sentido do discurso. Mas ainda assim, o sujeito descreve a informação oferecida, isto é, explica, reafirma e refina o discurso. Com efeito de introduzir uma ideia nova, a extensão refere-se ao acréscimo de novidades à oração, neste caso utiliza-se "e", "ou" ou "mas". E o realce ocupa-se da coerência do texto, ou seja, detalha o tempo, o espaço e a circunstância em que se deu o fato. O discurso do Inspetor Geral de Instrução Pública, adicionado ao relatório do presidente da Província de Goiás, Antero Cicero D’Assiz (1872), contempla a categoria coesão.

[...] Por acto de 6 de Junho foi demitido João da Affonseca e Silva, professor interino da parochia do Curralinho, por irregularidade de conducta; Por acto de 15 de Junho foi demitido, á bem do serviço publico, Manoel Alves Bandeira, professor interino da cidade da Palma. Por acto de 16 de Outubro foi demitido Joaquim Manoel Corrêa, professor vitalicio do Rio Verde, em virtude do disposto na ultima parte do art. 13 do Regulamento do $1^{\circ}$ de Janeiro de 1869. Por acto de 17 de Outubro foi demitido, á seu pedido, Francisco Ignacio de Farias Vivas, professor interino de Meiaponte. Por acto de 12 de Dezembro foi exonerado á seu pedido Antonio Felippe Berquó, professor do Curralinho. [...] (Relatorio do Inspetor de Instrução Geral da Pública Joaquim Vicente de Azevedo, 1872, p. 04).

Como observamos, o Inspetor de Instrução Joaquim Vicente de Azevedo, em seu relatório, por meio das expressões "fol" e "á bem" (substituível por, isto é), informa e explica (elaboração) ao presidente da Província de Goiás quais foram as demissões do serviço público. A inserção de "por", "em virtude" e "á seu" conectam os termos dando continuidade à frase. Neste caso, a articulação (extensão) tem o papel de construir a consequência que resultará na coerência na frase. Ao estabelecer a elaboração e a extensão, o sujeito fundamenta (realça) os fatores que levaram à remoção dos opositores. Para isso, Joaquim Vicente de Azevedo serve-se de "irregularidades de 
conducta", "art. 13 do Regulamento do $1^{\circ}$ de Janeiro de $1869^{\prime}$ e "pedido" para encadear a lógica das demissões apresentadas ao longo do discurso.

Parece que cada vez mais o comportamento dos professores preocupava os presidentes que detinham a regulamentação moral da época. Nesse sentido, os professores não estavam se comportando de maneira a cumprir com os padrões de moralidade e respeitabilidade vigentes (ROHDEN, 2001). Como sabemos, o conceito de moralidade é histórico, se transforma e evolui ao longo do tempo. A atipicidade da conduta, contemplada, em especial, no ensinamento de doutrinas imorais e antireligiosa, bem como a prática ou os consentimentos imorais, última parte do artigo 13 do Regulamento de Instrução Pública de 1869, sem dúvida estavam presentes na instrução pública, sobretudo na instrução primária. Decerto, a imoralidade praticada pelos professores representava uma afronta à ordem pública, então, inserir as mulheres no magistério reproduziria o conservadorismo e não atentaria contra a ordem do império.

A terceira e última categoria utilizada é a representação de atores sociais. Tratase de uma categoria de análise relacionada à performance dos atores nos discursos. Ramalho e Resende (2011, p. 153) defendem que as representações de atores sociais "podem ter implicações ideológicas", pois o modo como se concebe ou se analisa uma situação depende do conhecimento prévio, dos valores e da prática social do sujeito. A ideia geral nessa categoria é que os pontos de vista sobre os atores envolvidos podem resultar em exclusão ou inclusão. A representação dos atores sociais considera, ainda, que os sujeitos podem ter seus atributos apagados ou evidenciados, bem como podem ser representados também pela atividade que desempenham ou pelo julgamento a respeito do que são ou do que fazem. O discurso do Presidente da Província de Goiás Aristides de Souza Spinola, em 1879, declaradamente apaga a condição do professor ao referir-se como "fronte carregada" e "ferula em punho" e destaca a agência da professora ao relacioná-la à "brandura", "pacience", "dedicação" e "amor". Em outras palavras, o professorado feminino sobressairia aos "homens racionais responsáveis pela ordem social" (CAULFIELD, 2000, p. 179) pela "afabilidade de trato, benevolência, igualdade de humor" (BARREIROS, 1997, p. 101).

[...] E'preciso dar trabalho á mulher. Comecemos por facilitar-lhe os meios para o magisterio, não só de meninos como de meninas. Em Baltimore, nos Estados-Unidos, o numero de professoras excede ao de professores. A ideia de aproveitar as aptidões da mulher é tão seductora em theoria quanto apreciavel na pratica. Hoje que desapparece o systema de ferula e do terror, o opostolado do magisterio, apostulado de brandura, de pacience, de dedicação, de amor, quadra mais á mulher do que ao homem. A creança, que aborrece o livro por que abomina o mestre de fronte carregada, de ferula em punho, amando a mestra, amará a escola. Aqui mesmo, n'esta cidade, o observador notará a differença que vai entre a escola regida pela mulher, e a regida pelo homem, apesar da insufficientissima educação da mestra. [...] (Relatório do presidente da Província de Goiás, Aristides de Souza Spinola, 1879, p. 18) 
ROCHA, R. S.; ABREU, S. E. A. de

No âmbito da representação dos atores sociais, a inclusão pode ainda apresentar-se de três maneiras: nomeação, categorização por funcionalidade ou identificação. Na nomeação, como a própria denominação diz, os atores são representados pelo nome; na categorização os atores são retratados a partir das atividades ou profissão que desempenham, e na inclusão por identificação, os atores são representados pelo que "são". Nesse arranjo, leva-se em conta o sexo, a idade e as dimensões econômicas, sociais, demográficas e religiosas dos atores. No relatório do presidencial Aristides de Souza Spinola (1888), ele emprega o discurso do superintendente de escolas de Nova York (intertextualidade manifesta) para categorizar as mulheres por meio do ofício professora.

[..] Em um livro, que se tornou popular no Brasil, por causa de uma edição que delle deu-nos, em lingua vernacula, a typographia do Diario Oficial, (1) vem citadas, a respeito das professoras, as seguintes palavras de um superintendente das escolas de NovaYork: "A elevação de seu espirito se communica naturalemnte aos educandos, que estão em relação quotidiana com ellas; graciosas, brandas e puras, ellas os tornão brandos, puros e graciosas. A mulher, muito mais penetrante que o homem, conhece melhor do que elle o coração humano e particularmente o dos meninos. Ella os mantem no dever pela affeição, melhor do que fazem os professores com os seus relamentos e systemas de repressão. As advertencias ternas produzem mais efeito do que as ameaças e a fria logica dos homens. Enfim, podemos estar certos de que todo o menino, educado por professoras capazes, sahirá de suas mãos cheio de sentimentos incompativeis com uma existencia viciosa; terá coração sensível, inclinações delicadas, espirito vivo e subtil. Não tenho duvida de que o futuro será reconhecido aos imensos serviços que ellas terão prestado as nossas escolas". [...] (Relatório do presidente da Província de Goiás, Aristides de Souza Spinola, 1880 , p. 25)

O que percebemos também no texto é que não havia diferenciação entre a mulher da esfera privada da mulher pública, ora mãe ora professora. Assim, a naturalização para o trato com as crianças, relacionada à sua "essência", é colocada como uma incumbência útil para a função de professora. Nesse sentido, o presidente se posiciona favorável diante da chance de uma instrução pública erguida em outras bases. Consideramos que tais colocações estiveram pautadas em influências europeias e norteamericanas que chegavam ao país. A partir de então, a elite política, religiosa e educacional creditara às mulheres o esteio da família e, à medida que mãe e professora, a responsabilidade pelo futuro da nação. (BARREIROS, 1997, p. 94).

\section{ALGUMAS CONSIDERAÇÕES}

A proposta deste trabalho foi tentar responder o que (possivelmente) moveu o governo goiano a admitir apenas professoras para a regência das escolas mistas e se esse momento residiria no ponto de partida da suposta feminização do magistério em Goiás. Mesmo não havendo predominância entre os presidentes acerca da participação 
das mulheres no trabalho docente, em um período marcado por práticas conservadoras, alguns discursos baseados em experiências estrangeiras contribuíram para a Província de Goiás reexaminar o processo de ingresso de professores e habilitar as mulheres nas escolas mistas. Dessa forma, a feminização do magistério em Goiás não é um fenômeno recente, muito pelo contrário, começou a ser construído na década de 1870 , mas que alcançou visibilidade nas décadas de 1970/80 a partir de estudos de gênero e correntes teóricas não hegemônicas.

Artigo recebido em: 20/08/2020

Aprovado para publicação em: 18/11/2020

\section{ORDINARY SESSION: DISCOURSE ANALYSIS OF THE PRESIDENTS FROM GOIÁS'S PROVINCE IN THE CONSTRUCTION OF THE FEMINIZATION OF THE MAGISTERY IN THE XIX CENTURY}

ABSTRACT: In this paper we analyze the discourses of the presidents of the Province of Goiás for the construction of the feminization of teaching in the 19th century. The discussions are based mainly on the contributions of Bretas (1991), Brandão (2012), Charaudeau and Maingueneau (2012), Maingueneau (2008a and 2008c), Bakhtin (2010), Fairclough (2001) and Ramalho and Resende (2011). It is a qualitative investigation, with an exploratory objective and bibliographic and documentary procedures. The outcomes show, among others, that there was no tendency to insert women in the exercise of teaching, as well as the debate on gender was not set, but, it seems, of segregation based on the moral norm of the time. Therefore, the feminization of the teaching profession in the Province of Goiás was a construction fostered throughout Brazil Empire.

KEYWORDS: Feminization. Instruction. Goiás. Discourse. SESIÓN ORDINARIA: ANÁLISIS DE LOS DISCURSOS DE LOS PRESIDENTES DE LA PROVINCIA DE
GOIÁS EN LA CONSTRUCCIÓN DE LA FEMINIZACIÓN DE LA MAGISTERÍA EN EL SIGLO XIX

RESUMEN: En este artículo analizamos los discursos de los presidentes de la provincia de Goiás para la construcción de la feminización de la profesión docente en el siglo XIX. Las discusiones se basan principalmente en las contribuciones de Bretas (1991), Brandão (2012), Charaudeau y Maingueneau (2012), Maingueneau (2008a y 2008c), Bakhtin (2010), Fairclough (2001) y Ramalho y Resende (2011). Es una investigación cualitativa, con objetivo exploratorio y procedimientos bibliográficos y documentales. Los resultados muestran, entre otros, que no hubo tendencia a insertar a las mujeres en el ejercicio de la docencia, así como tampoco se planteó el debate sobre género, sino, al parecer, de segregación con base a la norma moral de la época. En este sentido, la feminización de la profesión docente en la provincia de Goiás fue una construcción impulsada en todo el Imperio brasileño. 
ROCHA, R. S.; ABREU, S. E. A. de.

PALABRAS CLAVE: feminización. Instrucción. Goiás Discurso.

\section{NOTAS}

1 - Os regulamentos consistiam em um conjunto de normas criadas pelo governo provincial com a função de organizar, disciplinar e controlar os assuntos relativos ao ensino. Desse modo, os regulamentos de instrução pública de Goiás (Regulamento sobre a Instrução Primária de 1856; Regulamento da Instrução Pública e Particular de Goiás de 1869; Regulamento da Instrução Pública de 1884; Regulamento da Instrução Pública de 1886; Regulamento para a Instrução Primária de Goiás de 1887 e Regulamento da Instrução Primária de Goiás de 1893) regimentavam a organização e a estrutura escolar e o modo de organizar, instruir e disciplinar o alunado e o corpo professoral (ABREU, 2006).

2 - As categorias de análise modalidade, coesão e representação de atores sociais derivadas da Análise do Discurso foram escolhidas, a partir da leitura sistemática dos dados, aspirando que o objeto se mostrasse no plano discursivo. Como o número de categorias aplicadas em uma análise depende do objetivo e da natureza do estudo, as categorias analíticas empregadas nesta investigação auxiliaram no percurso da descrição e da interpretação dos textos, manifestadas pelas posições sociais, culturais e ideológicas dos sujeitos, neste caso, dos presidentes da Província de Goiás. As categorias genéricas, como gêneros do discurso e intertextualidade, não aparecem associadas aos resultados por entendermos que são categorias amplas para integrar análise de discursos particulares.

3 - As fontes históricas são resumos de vários outros relatórios dos diversos setores do governo imperial de Goiás. Paralelamente, os relatórios das diferentes repartições públicas da província, como o Relatório do Inspetor Geral da Instrução Pública, estavam incorporados ao Relatório do Presidente da Província. Em linhas gerais, os documentos redigidos pelos presidentes apresentavam aos deputados da Assembleia Legislativa Provincial de Goiás as explicações sobre a situação, as necessidades e o progresso da província. Ainda sobre esse aspecto, a série documental (1870-1884) foi localizada no site da Universidade de Chicago, mas pode ser acessada também no Instituto de Pesquisa e Estudos Históricos do Brasil Central (IPEH-BC), órgão ligado à Sociedade Goiana de Cultura da Pontifícia Universidade Católica de Goiás, em Goiânia.

\section{REFERÊNCIAS}

ABREU, Sandra Elaine Aires de. A Instrução Primária na Província de Goiás no Século XIX. 2006. Tese (Doutorado em Educação: História, Política e Sociedade). Pontifícia Universidade Católica de São Paulo, São Paulo, 2006.

BARREIROS, Márcia Maria da Silva. Educação, cultura e lazer das mulheres de elite em Salvador (1890-1930). 1997. Dissertação (Mestrado em História). Universidade Federal da Bahia, Salvador, 1997.

BAKHTIN, M. Os gêneros do discurso. In: Estética da criação verbal. Introdução e tradução do russo Paulo Bezerra. 5. ed. São Paulo: Martins Fontes, 2010. p. 261-306.

BRANDÃO, H. H. N. Analisando o discurso. São Paulo: Museu da Língua Portuguesa/Estação da Luz, 2012. Disponível em: 
http://www.museulinguaportuguesa.org.br/colunas_interna.php?id_coluna=1. Acesso em: 25 jul. 2012.

BRASIL. Decreto Imperial de 15 de outubro de 1827. Manda criar escolas de primeiras letras em todas as cidades, vilas e lugares mais populosos do império. Brasília: Câmara dos Deputados. Disponível em: https://www2.camara.leg.br/legin/fed/lei_sn/18241899/lei-38398-15-outubro-1827-566692-publicacaooriginal-90222-pl.html. Acesso em: 4 fev. 2020.

BRASIL. Decreto Lei $n^{\circ} 16$ de 12 de agosto de 1834. Alterações e adições à Constituição Política do Império. Brasília: Casa Civil. Disponível em: http://www.planalto.gov.br/ccivil_03/leis/lim/LIM16.htm. Acesso em: 4 fev. 2020.

BRETAS, G. F. História da instrução pública em Goiás. Goiânia: UFG, 1991. p. 15-422.

CAULFIELD, Sueann. Em defesa da honra: moralidade, modernidade e nação no Rio de Janeiro (1918-1940). Campinas: Editora da Unicamp, 2000.

CHARAUDEAU, P.; MAINGUENEAU, D. Análise do Discurso. In: Dicionário de análise do discurso. São Paulo: Contexto, 2012. p. 43-47.

FAIRCLOUGH, N. Intertextualidade. In: Discurso e mudança social. Coordenação da tradução e revisão técnica Izabel Magalhães. Brasília: UnB, 2001. p. 133-174.

FAIRCLOUGH, N. Análise textual: a construção das relações sociais e do "eu". In: Discurso e mudança social. Coordenação da tradução e revisão técnica Izabel Magalhães. Brasília: UnB, 2001. p. 175-210.

D’AVILA, Jerry. Diploma de brancura: política social e racial no Brasil. Tradução Cláudia Sant'Ana Martins. São Paulo: UNESP, 2006. p. 47-240.

GOIÁS. Relatório do presidente da província de Goiás, José Rodrigues Jardim, 1835. Apresentado à Assembleia Legislativa e Goyaz na Sessão Ordinária de 1835. Meyaponte: Typographia Provincial, $1835 . \quad$ Disponível em: http://wwwcrl.uchicago.edu/content/brazil/goi.htm/. Acesso em: 16 fev. 2020.

GOIÁS. Relatório do presidente da província de Goiás, Ernesto Augusto Pereira, 1869. Apresentado à Assembleia Legislativa e Goyaz na Sessão Ordinária de 1869. Meyaponte: Typographia Provincial, 1869. Disponível em: http://wwwcrl.uchicago.edu/content/brazil/goi.htm/. Acesso em: 16 fev. 2020.

GOIÁS L. Relatório do presidente da província de Goiás, Antero Cicero D’Assiz, 1871. Apresentado à Assembleia Legislativa e Goyaz na Sessão Ordinária de 1871. Meyaponte: 
ROCHA, R. S.; ABREU, S. E. A. de

Typographia Provincial, $1871 . \quad$ Disponível em: http://wwwcrl.uchicago.edu/content/brazil/goi.htm/. Acesso em: 16 fev. 2020.

GOIÁS. Relatório do presidente da província de Goiás, Antero Cicero D’Assiz, 1872. Apresentado à Assembleia Legislativa e Goyaz na Sessão Ordinária de 1872. Meyaponte: Typographia Provincial, $1872 . \quad$ Disponível em: http://wwwcrl.uchicago.edu/content/brazil/goi.htm/. Acesso em: 16 fev. 2020.

GOIÁS. Relatório do presidente da província de Goiás, Luiz Augusto Crespo, 1878. Apresentado à Assembleia Legislativa e Goyaz na Sessão Ordinária de 1878. Meyaponte: Typographia Provincial, $1878 . \quad$ Disponível em: http://wwwcrl.uchicago.edu/content/brazil/goi.htm/. Acesso em: 16 fev. 2020.

GOIÁS. Relatório do presidente da província de Goiás, Aristides de Souza Spinola, 1879. Apresentado à Assembleia Legislativa e Goyaz na Sessão Ordinária de 1879. Meyaponte: Typographia Provincial, 1879. Disponível em: http://wwwcrl.uchicago.edu/content/brazil/goi.htm/. Acesso em: 16 fev. 2020.

GOIÁS. Relatório do presidente da província de Goiás, Aristides de Souza Spinola, 1880. Apresentado à Assembleia Legislativa e Goyaz na Sessão Ordinária de 1880 . Meyaponte: Typographia Provincial, 1880. Disponível em: http://wwwcrl.uchicago.edu/content/brazil/goi.htm/. Acesso em: 16 fev. 2020.

GOIÁS. Lei n 13 de 23 de junho de 1835. A $1^{\circ}$ Lei Goiana sobre Instrução Pública. In: BRETAS, G História da ISTRUCÇÃO Pública em Goiás. Coleção de Documentos Goianos nº 21. Goiânia: CEGRA/UFG e ABEU, p. 615 - 618. Goiânia- Goiás.

GOIÁS. Resolução n 7 de 22 de novembro de 1855. Dispõe sobre regulamento de Instrucção Primária de 1856. Goiás, GO: Rede de Estudos de História da Educação de Goiás, 2012, 1 CD-ROM.

GOIÁS. Lei no 414 de 9 de novembro de 1868. Dispõe sobre regulamento de Instrucção Pública e Particular de 1869. Goiás, GO: Rede de Estudos de História da Educação de Goiás, 2011, 1 CD-ROM.

GOIÁS. Ato n 3397 de 9 de abril de 1884. Dispõe sobre regulamento de Instrucção Pública de 1884. Goiás, GO: Rede de Estudos de História da Educação de Goiás, 2011, 1 CD-ROM.

GOIÁS. Decreto no 26 de 23 de dezembro de 1893. Dispõe sobre regulamento de Instrucção Primaria do Estado de Goyas de 1893. Goiás, GO: Rede de Estudos de História da Educação de Goiás, 2011, 1 CD-ROM.

MAINGUENEAU, D. Os discursos constituintes. In: Cenas da enunciação. Organização Sírio Possenti e Maria Cecília Perez de Souza-e-Silva. São Paulo: Parábola, 2008a. p. 37-54. 
ORLANDI, E. P. Sujeito, história, linguagem. In: Análise de discurso: princípios e procedimentos. 5. ed. Campinas: Pontes, 2003. p. 23-56.

RAMALHO, V.; RESENDE, V. de M. Análise textual aplicada: categorias analíticas e exemplos de análise. In: Análise de discurso (para a) crítica: o texto como material de pesquisa. Campinas: Pontes, 2011. p. 111-156.

ROHDEN, Fabíola. Honra no Brasil: da moral sexual à imagem da nação. Revista História Ciência Saúde - Manguinhos, Rio de Janeiro (RJ), v. 8, n. 3, p. 767-773, set./dez. 2001. DOI: http://dx.doi.org/10.1590/S0104-59702001000400016. Disponível em: https://www.scielo.br/scielo.php?script=sci_arttext\&pid=S0104-59702001000400016. Acesso em: 27 nov. 2020.

Rodrigo Silva Rocha: Mestrando do Programa de Pós-Graduação Interdisciplinar em Educação, Linguagem e Tecnologias da Universidade Estadual de Goiás. Bacharel em Administração pelo Instituto de Educação Superior Unyahna de Barreiras. Supervisor administrativo, Auditor e Representante da Qualidade ISO 9001:2015.

Orcid: https://orcid.org/0000-0002-9008-1320

E-mail: rodrigosilvarocha@hotmail.com

Sandra Elaine Aires de Abreu: Estágio Pós-Doutoral em Educação pela Universidade Federal de Uberlândia (2014). Doutorado em Educação: História, Política, Sociedade pela Pontifícia Universidade Católica de São Paulo (2006). Mestrado em Educação, pela Universidade Federal de Goiás (1997). Especialização em História Econômica (1990), pela Associação Educativa Evangélica. Graduada em Pedagogia pela Associação Educativa Evangélica (1986) e em História pela Universidade Federal de Goiás (1987). Docente do Ensino Superior da Universidade Estadual de Goiás e do Programa de Pós-Graduação Interdisciplinar em Educação Linguagem e Tecnologias (PPG-IELT/UEG) e do Centro Universitário de Anápolis (Uni EVANGÉLICA). Líder do Grupo Goiano de Estudos e Pesquisa em História da Educação (GGEPHE).

Orcid: https://orcid.org/0000-0001-6242-961X

E-mail:sandraeaa@yahoo.com.br

Este periódico utiliza a licença Creative Commons Attribution 3.0, para periódicos de acesso aberto (Open Archives Iniciative - OAI). 